\title{
Influence of honey addition on the bioaccessibility of phenolic contents and antioxidant capacities of different coffee types
}

\author{
Engin CELEP, Erdem YEŞİLADA
}

\begin{abstract}
This study was designed to assess the effect of honey addition to the antioxidant capacity and in vitro bioaccessibility of phenolic content of both brewed and soluble coffee. Floral and pine honey were used in the assay. The antioxidant capacities of the samples were evaluated with three different methods: DPPH radical scavenging activity, cupric reducing capacity and total antioxidant capacity tests. In order to measure the antioxidant metabolites of the samples, total phenolic and flavonoid contents were appraised. In vitro gastrointestinal digestion simulation procedure was conducted to mimic the physiochemical and
\end{abstract}

biochemical factors of the gastrointestinal tract. During the digestion process, components in the food matrix are exposed to significant structural changes and certain amount of them are effectively absorbed and reach the circulation. To that end, the importance of studies concerning the simulated gastrointestinal digestion increases. The results of this study revealed that honey addition to coffee samples induced increases in antioxidant capacities, total phenolic and flavonoid contents.

Key words: Coffee; honey; phenolic content; antioxidant capacity; in vitro digestion
Engin Celep, Erdem Yeşilada

Department of Pharmacognosy, Faculty of Pharmacy, Yeditepe University, Atasehir, 34755, Istanbul, Turkey

Corresponding Author:

Engin Celep

e-mail: ecelep@yeditepe.edu.tr

Submitted / Gönderilme: 02.05.2017 Revised / Düzeltme: 16.06.2017 Accepted / Kabul: $\quad 20.06 .2017$

How to cite this article : Celep E, Yeşilada E. Influence of honey addition on the bioaccessibility of phenolic contents and antioxidant capacities of different coffee types. Marmara Pharm J 2017; 21 (4): 906-914

\section{Introduction}

Since its discovery in around the sixth century by Ethiopian shepherds, coffee has become the most consumed beverage in the world [1]. This popularity arises from its pleasant aroma and taste as well as its psychoactive properties due to caffeine content. In recent years, there has been a growing interest on the association between coffee and healthcare [2]. The findings of recent epidemiological studies indicated the linkage between coffee consumption and the prevention of several chronic diseases, including diabetes, liver problems [3], Parkinson's and dementia [4], and cardiovascular problems [5]

All of these health benefits are correlated with its antioxidant activity [6]. Coffee has been known as a vast source of antioxidants [7]. The phenolic compounds (mostly caffeoylquinic acids) and Mailard reaction products, which are formed during roasting process, are known to contribute to the high antioxidant capacity of coffee $[1,2,8]$.

In addition to the traditional coffee brewing methods, the market for soluble (ready-to-drink) coffee has shown an increase recently. Even though, they lack some of the aromatic and taste properties of freshly brewed coffee, soluble coffee 
products have been introduced as an alternative to traditional methods [9]. Especially in Turkey, they are more popular than any other brewed coffee, with the only exception of Turkish coffee [10].

Honey can be regarded as one of the oldest remedies and has been utilized as a health giving substance since ancient times. The records on its medical utilization date back to 3000 B.C. The first written data about honey as a remedy found up-to-date is Edwin Smith papyrus (2600-2200 BC), where it was recorded to be used in wound healing. The use of honey was mentioned in Ayurvedic, Chinese and Roman medicine, too [11]. Moreover, the Greek physician and herbalist Dioscorides mentioned honey as a vehicle for carrying the therapeutic agents in his Materia Medica [12]. The World Health Organization cited honey as a potential treatment against the symptoms of sore throat, cough and upper respiratory tract infections [13].

Honey can roughly be classified as floral and honeydew honeys based on the source and formation. In contrast to floral honey, honeydew honey is produced from the secretion of insects living on the plants. Pine, oak and fir honeys can be named as examples of such honeys. Pine honey is the most typical form of honeydew in Turkey. It is produced by honeybees from the secretion of an insect living on Turkish pine (Pinus brutia) [14].

The composition of honey and the amount of these ingredients are mainly based on the floral characteristics of the area where honeybees gather pollen. Honey is reported to consist of nearly 200 compounds. It is mainly composed of sugars (30\% glucose, $40 \%$ fructose, $5 \%$ sucrose) together with amino acids, vitamins, mineral, enzymes and aromatic compounds. In addition to these molecules, some major antioxidants such as phenolic compounds, carotenoids and some other phytochemicals are also found in the composition of honey $[11,15,16]$. Recent studies displayed significant antioxidant activity of several different honey samples from different parts of the world [17-19]. In addition, it has been reported to act on antioxidant enzymes [20], and to increase cytokine release [15]. Hence, honey addition as a coffee supplement instead of sugar is supposed to influence not only the aroma and taste of the beverage but may also improve the antioxidant potential, since both coffee and honey contain bioactive phenolics.

However, it is a well-known fact that once administered orally, molecules have to be absorbed and distributed in order to exert their biological properties at the cellular level. Only the molecules that manage to tolerate the physicochemical conditions through the gastrointestinal tract and to penetrate through the intestinal membrane may induce pharmacological activity. In vitro digestion models have been designed to simulate the GI tract in order to evaluate the bioavailability of bioactive compounds involving the addition of digestive enzymes, bile salts, and adjusting $\mathrm{pH}$ and temperature. Besides, a final dialysis step is carried out to simulate the intestinal permeability $[2,21]$.

Table 1. Total phenolic contents of coffee samples before and after in vitro gastrointestinal digestion ${ }^{\mathrm{A}}$

\begin{tabular}{|c|c|c|c|c|}
\hline Samples & ND & PG & IN & OUT \\
\hline S.C. ${ }^{\mathrm{B}}$ & $98,34 \pm 4,71^{\mathrm{a}}$ & $59,31 \pm 2,64^{\text {ax }}$ & $21,77 \pm 1,96^{\text {a* }}$ & $31,93 \pm 0,85^{a \star}$ \\
\hline S.C. + F.H. & $108,64 \pm 3,67^{\mathrm{b}}$ & $61,24 \pm 1,37^{\text {ax }}$ & $28,29 \pm 0,47^{\mathrm{b} *}$ & $39,61 \pm 1,37^{b \star}$ \\
\hline S.C. + P.H. & $110,34 \pm 2,91^{b}$ & $70,19 \pm 2,96^{b \star}$ & $35,70 \pm 1,62^{c *}$ & $51,27 \pm 0,28^{c x}$ \\
\hline B.C. & $101,27 \pm 2,35^{\mathrm{a}}$ & $75,87 \pm 4,71^{c \star}$ & $36,24 \pm 2,08^{c *}$ & $67,84 \pm 4,39^{d x}$ \\
\hline B.C. + F.H. & $119,54 \pm 0,68^{c}$ & $90,16 \pm 2,12^{\mathrm{d} \star}$ & $40,61 \pm 0,84^{\mathrm{d} \star}$ & $69,39 \pm 3,51^{\mathrm{d} x}$ \\
\hline B.C. + P.H. & $126,16 \pm 4,24^{d}$ & $95,82 \pm 1,37^{e x}$ & $45,28 \pm 1,77^{e \star}$ & $76,63 \pm 1,68^{\text {ex }}$ \\
\hline
\end{tabular}

${ }^{\text {A }}$ Results were expressed as the mean of triplicates \pm standard deviation (S.D.) and as mg gallic acid equivalents (GAE) in $1 \mathrm{~g}$ sample.

${ }^{B}$ The abbreviations for samples are S.C.: soluble coffee, F.H.: flower honey, P.H.: pine honey, B.C.: brewed coffee. ND: non-digested, PG: postgastric, IN: serum available, OUT: colon available

a-e Different letters in a column indicate significance $(p<0.05)$

${ }^{*} p<0.05$ (compared to nondigested sample) 
Table 2. Total flavonoid contents of coffee samples before and after in vitro gastrointestinal digestion ${ }^{\mathrm{A}}$

\begin{tabular}{|c|c|c|c|c|}
\hline Samples & ND & PG & IN & OUT \\
\hline S.C. ${ }^{\text {B }}$ & $38,43 \pm 0,68^{\mathrm{a}}$ & $23,16 \pm 1,92^{a \star}$ & $8,31 \pm 0,12^{a \star}$ & $17,19 \pm 2,44^{\text {ax }}$ \\
\hline S.C. + F.H. & $45,71 \pm 2,78^{\mathrm{b}}$ & $30,18 \pm 2,26^{\text {bct }}$ & $14,27 \pm 1,54^{b \star}$ & $24,24 \pm 1,39^{b *}$ \\
\hline S.C. + P.H. & $55,49 \pm 2,20^{c}$ & $34,61 \pm 3,35^{b \star}$ & $20,31 \pm 2,68^{c *}$ & $31,95 \pm 3,11^{\mathrm{cd} x}$ \\
\hline B.C. & $44,42 \pm 1,49^{\mathrm{b}}$ & $28,43 \pm 1,64^{c \star}$ & $13,43 \pm 1,36^{b *}$ & $22,63 \pm 0,42^{b *}$ \\
\hline B.C. + F.H. & $51,26 \pm 3,07^{\mathrm{d}}$ & $32,31 \pm 1,18^{b *}$ & $23,16 \pm 4,04^{c *}$ & $28,62 \pm 2,27^{c *}$ \\
\hline B.C. + P.H. & $59,17 \pm 2,86^{\mathrm{c}}$ & $40,67 \pm 0,89^{d x}$ & $27,77 \pm 2,14^{\mathrm{d} x}$ & $34,41 \pm 2,43^{\mathrm{d} x}$ \\
\hline
\end{tabular}

${ }^{\text {A }}$ Results were expressed as the mean of triplicates \pm standard deviation (S.D.) and as mg quercetin equivalents (QE) in $1 \mathrm{~g}$ sample.

${ }^{\text {В }}$ The abbreviations for samples are S.C.: soluble coffee, F.H.: flower honey, P.H.: pine honey, B.C.: brewed coffee. ND: non-digested, PG: postgastric, IN: serum available, OUT: colon available

${ }^{*} p<0.05$ (compared to nondigested sample)

In the light of all of these data, this study was planned to show any possible synergistic antioxidant interaction between coffee and honey components, any difference between floral pine or honey pine and brewed coffee or soluble coffee following the submission to in vitro gastrointestinal simulation model. For this purpose, total phenolic and flavonoid contents of the samples together with different aspects of antioxidant activity such as free radical scavenging activity and metal reducing activity were appraised.

\section{Results}

\subsection{Total phenolic and flavonoid contents of the samples}

Total phenolic and flavonoid contents of brewed and soluble coffee samples with/out floral or pine honey were presented in Table 1 and 2, respectively. Among the samples, the highest phenolic content in gallic acid equivalents was determined in brewed coffee after addition of pine honey $(126.16 \pm 4.24$ $\mathrm{mg} / \mathrm{g}$ sample, $\mathrm{p}<0.05)$. In terms of soluble coffee, the sample with pine honey addition possessed the highest amount of total phenolic content $(110.34 \pm 3.67 \mathrm{mg} / \mathrm{g}$ sample, $\mathrm{p}<$ $0.05)$. This trend did not change after in vitro gastrointestinal digestion. Our results revealed significant decreases $(\mathrm{p}<$ 0.05 ) in total phenolic and flavonoid contents for PG, IN and OUT fractions. All IN fractions seemed to have the lowest amount in both phenolic and flavonoid contents. Besides, significant increases $(\mathrm{p}<0.05)$ were seen in both IN and OUT fractions of both coffee types after honey additions. Table 1 and 2 indicated that total phenolic and flavonoid contents of the coffee samples with pine honey were significantly higher than those with floral honey in terms of both IN and OUT fraction $(\mathrm{p}<0.05)$. Honey addition induced significant increases in the total phenolic and flavonoid content of the serum-available fraction (IN).

\subsection{Antioxidant capacities}

The results of total antioxidant capacity test were tabulated in Table 3. As expected, the antioxidant capacity of the coffee samples displayed a tendency towards increase after the addition of honey samples ( $\mathrm{p}<0.05)$. The brewed coffee after pine honey addition was found to possess the highest antioxidant capacity in respect to total antioxidant capacity test (392.54 $\pm 1.67 \mathrm{mg} \mathrm{AAE} / \mathrm{g}$ dry ext.). The serum-available samples (IN) seemed to increase significantly for both soluble and brewed coffee after the addition of floral and pine honey. Particularly pine honey addition dramatically raised the total antioxidant capacities in both serum and colon available samples for each coffee types. According to results given in Table 4, free radical scavenging activity of coffee samples were also increased with honey addition ( $\mathrm{p}$ $<0.05)$. However, there is no significant difference in free radical scavenging activity between floral or pine honey addition to the brewed coffee samples. The activity of the serum available content significantly increased after honey additions. Surprisingly, no significant change was observed in OUT fraction of brewed coffee after floral honey addition, but pine honey significantly increased the radical 
Table 3. Total antioxidant capacities of coffee samples before and after in vitro gastrointestinal digestion ${ }^{\mathrm{A}}$

\begin{tabular}{|c|c|c|c|c|}
\hline Samples & ND & PG & IN & OUT \\
\hline S.C. ${ }^{\text {B }}$ & $174,86 \pm 4.03^{\mathrm{a}}$ & $126,49 \pm 2,38^{\text {a* }}$ & $68,16 \pm 0,68^{a *}$ & $89,66 \pm 1,36^{a *}$ \\
\hline S.C. + F.H. & $233,39 \pm 5,74^{\mathrm{b}}$ & $158,97 \pm 4,78^{\mathrm{b} *}$ & $92,24 \pm 4,39^{b *}$ & $124,39 \pm 2,67^{b *}$ \\
\hline S.C. + P.H. & $256,17 \pm 8,33^{c}$ & $173,29 \pm 5,23^{c *}$ & $110,21 \pm 5,31^{\mathrm{cd} x}$ & $139,24 \pm 2,29^{c *}$ \\
\hline B.C. & $189,55 \pm 6,49^{d}$ & $131,53 \pm 2,19^{a \star}$ & $75,16 \pm 3,66^{\text {e* }}$ & $101,66 \pm 5,63^{\mathrm{d} x}$ \\
\hline B.C. + F.H. & $264,61 \pm 5,83^{c}$ & $203,46 \pm 4,33^{\mathrm{d} *}$ & $104,39 \pm 2,57^{c *}$ & $189,34 \pm 4,56^{\mathrm{e} *}$ \\
\hline B.C. + P.H. & $288,32 \pm 4,37^{\mathrm{e}}$ & $214,88 \pm 7,69^{\text {ex }}$ & $115,64 \pm 1,86^{\mathrm{d} x}$ & $192,64 \pm 2,76^{e x}$ \\
\hline
\end{tabular}

${ }^{\mathrm{A}}$ Results were expressed as the mean of triplicates \pm standard deviation (S.D.) and as $\mathrm{mg}$ ascorbic acidequivalents (AAE) in $1 \mathrm{~g}$ sample.

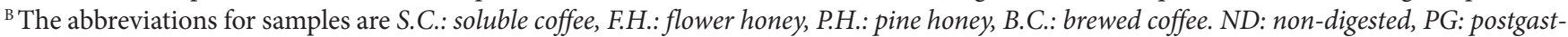
ric, IN: serum available, OUT: colon available

${ }^{*} p<0.05$ (compared to nondigested sample)

scavenging activity of the colon available content. The metal reducing capacity, which is another important parameter in evaluating the antioxidant activity, was determined with CUPRAC method. The results were presented in Table 5. Again, floral honey addition induced no significant raise in OUT fraction. However, pine honey contributed significantly to CUPRAC activity of coffee samples. It also should be noted that the percent ratio of the increases in metal reducing activity were found to be lower than those of radical scavenging activity.

\section{Discussion}

Coffee is one of the most popular and widely consumed beverages in the world, and regarded as one of the wealthiest sources of antioxidant compounds in human diet. Many studies have expressed that phenolic compounds found in coffee are the principal molecules responsible for the antioxidant activity leading to protection from chronic diseases mentioned earlier [8]. Among the various types of coffee beverages, soluble coffee and brewed coffee are the most widely consumed. Therefore, this study was designed

Table 4. DPPH radical scavenging activities of coffee samples before and after in vitro gastrointestinal digestion ${ }^{\mathrm{A}}$

\begin{tabular}{|c|c|c|c|c|}
\hline Samples & ND & PG & IN & OUT \\
\hline S.C. ${ }^{B}$ & $305,62 \pm 4,60^{\mathrm{a}}$ & $216,19 \pm 4,92^{\mathrm{a} \star}$ & $93,24 \pm 3,64^{\text {ax }}$ & $144,13 \pm 3,72^{a \star}$ \\
\hline S.C. + F.H. & $368,11 \pm 2,55^{\mathrm{b}}$ & $249,78 \pm 3,28^{\mathrm{b} *}$ & $112,39 \pm 2,19^{b *}$ & $164,34 \pm 2,46^{b \star}$ \\
\hline S.C. + P.H. & $375,26 \pm 2,74^{c}$ & $261,27 \pm 1,35^{c *}$ & $127,16 \pm 4,23^{c \star}$ & $196,44 \pm 3,19^{c *}$ \\
\hline B.C. & $354,16 \pm 3,08^{\mathrm{d}}$ & $245,31 \pm 4,19^{b x}$ & $109,43 \pm 3,66^{\mathrm{b} *}$ & $199,73 \pm 0,87^{\text {c* }}$ \\
\hline B.C. + F.H. & $387,39 \pm 2,64^{\mathrm{e}}$ & $264,21 \pm 2,58^{c *}$ & $131,21 \pm 3,82^{2 \star}$ & $201,74 \pm 2,73^{c \star}$ \\
\hline B.C. + P.H. & $392,54 \pm 1,67^{\mathrm{e}}$ & $288,91 \pm 3,17^{\mathrm{d} *}$ & $149,92 \pm 3,25^{\mathrm{d} x}$ & $277,31 \pm 5,94^{\mathrm{d} x}$ \\
\hline
\end{tabular}

${ }^{\text {A }}$ Results were expressed as the mean of triplicates \pm standard deviation (S.D.) and as $\mathrm{mg}$ ascorbic acid equivalents (AAE) in $1 \mathrm{~g}$ sample.

${ }^{\text {B }}$ The abbreviations for samples are S.C.: soluble coffee, F.H.: flower honey, P.H.: pine honey, B.C.: brewed coffee. ND: non-digested, PG: postgastric, IN: serum available, OUT: colon available

${ }^{\star} p<0.05$ (compared to nondigested sample) 
Table 5. Cupric ion reducing capacities (CUPRAC) of coffee samples before and after in vitro gastrointestinal digestion ${ }^{\mathrm{A}}$

\begin{tabular}{|c|c|c|c|c|}
\hline Samples & ND & PG & IN & OUT \\
\hline S.C. ${ }^{\text {B }}$ & $142,07 \pm 4,28^{\mathrm{a}}$ & $85,43 \pm 1,33^{\text {a }}$ & $42,38 \pm 1,67^{a \star}$ & $68,30 \pm 2,84^{\text {a }}$ \\
\hline S.C. + F.H. & $155,16 \pm 3,53^{\mathrm{b}}$ & $94,26 \pm 0,88^{b *}$ & $51,39 \pm 3,22^{b \star}$ & $73,11 \pm 1,44^{\mathrm{ab} \star}$ \\
\hline S.C. + P.H. & $158,42 \pm 4,11^{\mathrm{b}}$ & $96,49 \pm 4,27^{b *}$ & $50,87 \pm 1,45^{b *}$ & $76,28 \pm 1,78^{\text {bc }}$ \\
\hline B.C. & $164,53 \pm 1,26^{c}$ & $102,39 \pm 2,51^{c *}$ & $49,12 \pm 2,26^{b \star}$ & $80,36 \pm 3,29^{\mathrm{c} d} x$ \\
\hline B.C. + F.H. & $177,62 \pm 2,75^{\mathrm{d}}$ & $113,72 \pm 1,87^{\mathrm{d} x}$ & $54,64 \pm 3,51^{\text {bct }}$ & $85,15 \pm 3,72^{\mathrm{d} *}$ \\
\hline B.C. + P.H. & $180,49 \pm 2,18^{\mathrm{d}}$ & $120,18 \pm 3,07^{\text {ex }}$ & $57,19 \pm 1,57^{c *}$ & $100,83 \pm 3,64^{e x}$ \\
\hline
\end{tabular}

${ }^{A}$ Results were expressed as the mean of triplicates \pm standard deviation (S.D.) and as $\mathrm{mg}$ ascorbic acidequivalents (AAE) in $1 \mathrm{~g}$ sample.

${ }^{\text {В }}$ The abbreviations for samples are S.C.: soluble coffee, F.H.: flower honey, P.H.: pine honey, B.C.: brewed. ND: non-digested, PG: postgastric, IN: serum available, OUT: colon available

${ }^{*} p<0.05$ (compared to nondigested sample)

to investigate the change in the total phenolic and flavonoid contents and the antioxidant potentials of both soluble and brewed coffee, before and after floral honey and pine honey as a sweetener. For this purpose, the coffee samples were prepared following the usual procedures by the public. The results of this study doubtlessly stated that brewed coffee has higher phenolic content (especially in terms total flavonoid content, $\mathrm{p}<0.05)$ and antioxidant activity $(\mathrm{p}<0.05)$ than soluble coffee. During the production of soluble coffee samples, the coffee beans undergo a series of chemical changes that cause a loss in their original physicochemical properties. Especially, the acid-base equilibrium is affected, resulting in variations in the chemical structures of antioxidant compounds [9]. Moreover, the roasting process is also known to cause degradation of phenolic compounds [22], resulting in variations in the antioxidant capacity. Nevertheless, studies showed that coffee contains some nonphenolic compounds with high antioxidant capacity such as melanoidins, which are originated during roasting process as a result of Mailard reaction [9]. Also, caffeine is known to be a powerful antioxidant, itself [23]. In addition to a vast number of experimental studies [1,24], Chen and Kotani [25] have recently demonstrated the clear association with daily coffee consumption and reduced oxidative stress in women.

Preparation techniques of coffee beverages take part in the variations of their composition as well as processing such as roasting, as mentioned earlier. A majority of consumers prefer coffee with additives such as sweeteners, creamers or milk [26]. A recent meta-analysis displayed that regular consumption of beverages with sugar has been linked to the rise in obesity and diabetes cases as well as tooth decay [27]. Besides, artificial sweeteners such as aspartame and saccharine are thought to possess some potential side effects in spite of the conflicting data [28]. Moreover, recent studies stated the interaction between frequent consumption of sweetened beverages and higher prevalence of mental problems [29]. Another epidemiological study also revealed the higher risk of depression in coffee drinkers who use artificial sweeteners compared to those who do not [4]. Bouchard et al. demonstrated that adding artificial sweeteners to coffee cause higher body mass index and waist circumference than not adding [30].

The results of our study indicated that addition of both floral and pine honey elevated the phenolic content and the antioxidant capacity of both soluble and brewed coffee. The antioxidant potential of honey has been declared by a vast number of researchers using different methods. Recently, Can et al. [19] and Petretto et al. [18] reported high in vitro antioxidant capacity of various floral and honeydew honey samples from different regions, significantly correlated with phenolic content. These results also match with our findings, correlating with the increase in the total phenolic and flavonoid content of coffee samples after honey addition. In our study, the addition of pine honey increased these parameters a bit more than floral honey addition. Studies demonstrated that the antioxidant activity might vary 
depending on the floral origin of the honey due to changes in its chemical composition [19]. Ozdatl et al. stated that they observed the same increase in the total antioxidant capacity of herbal teas after the addition of both floral and pine honeys [31]. A wide range of constituents takes part in the antioxidant potential of honey, including not only phenolics, but also vitamins, carotenoids, enzymes such as catalase and peroxidase, and products of Mailard reaction, which are also formed in coffee beans after roasting process. Nonetheless, researchers suggested that phenolic compounds play the major role in the antioxidant potential of honey [18]. Furthermore, it has been claimed that the colour of honey is also significantly correlated with the antioxidant capacity of honey [32].

The findings of recent studies demonstrated that the increase in the antioxidant capacity is not the only synergistic effect of coffee and honey combination. In a double-blinded randomized clinical trials, authors regarded the "coffee plus honey regimen" as the most effective model for the treatment of oral mucositis, in comparison to steroidal drugs and honey alone [15]. Coffee-honey combination was presented to be very effective against persistent post-infectious cough in another clinical trial [33].

As discussed earlier, the biological activity of a phytochemical is directly influenced by its bioavailability in the body. The gastrointestinal tract is the primary site for the synergistic action of these antioxidant molecules. Throughout the digestion process, antioxidant compounds undergo physicochemical alterations that may cause variations in their biological activities. Therefore, studies that ignore these changes may lead to deficient results. In vitro simulation of gastrointestinal digestion provides an evidence for the bioavailability of antioxidants in coffee and honey. Although this method does not include every step of natural digestion process, it ensures the screening of a wide range of samples and is generally used to mimic the physicochemical modifications associated with GI digestion [34, 35]. Additionally, a dialysis model with a cellulose membrane was used in this study to determine the bioavailability of antioxidant molecules and to observe their possible effects on colon. Non-digested forms of the samples were included in the study in order to perform comparisons between the undigested and digested samples. The concentrations of non-digested samples were adjusted to the same concentrations with the digested samples. Therefore, each step of dilutions were cautiously monitored and noted.

The results of our study showed significant decreases in total phenolic and flavonoid contents and also in free radical scavenging activity and metal reducing capacities of coffee and coffee plus honey samples after subjected to in vitro digestion. The reason for such decreases in total phenolic and flavonoid contents might be due to $\mathrm{pH}$ variations during the digestion process, particularly the alkaline media of the intestines. This decline might also be linked to the influence of gastrointestinal enzymes, since they cause the liberation of phenolics from the sample matrix. Nevertheless, the increases in IN (serum-available) fractions of coffee plus honey combinations with regard to those of coffee alone were observed $(\mathrm{p}<0.05)$. This may lead to the assumption that the phenolic compounds of both floral and pine honey are readily bioavailable. Significant decreases in total phenolic contents of various samples after in vitro simulation model of digestion were reported before by several authors [34, 36]. Furthermore, Podio et al. also reported significant decline in total phenolic content of coffee samples after dialysis in a similar simulation model. The results of the same study match with our findings, such as: free radical scavenging activity and metal reducing capacity of coffee and coffee plus chicory were dramatically decreased. The sequences trend among the samples did not change before and after in vitro digestion process, neither did ours [2]. The observed decreases in the antioxidant capacity seems to be due to the losses in phenolic concentrations after digestion process with regard to nondigested samples, since these are directly correlated with each other, as discussed earlier in the text. In addition, the possible interaction of antioxidant phenolics with various minerals and volatile compounds should also be taken into consideration [37].

\section{Conclusion}

This study is believed to be the first study about the effects of honey addition to the phenolic content and the antioxidant capacities of both brewed and soluble coffee. At this occasion, the difference between these parameters of brewed and soluble coffee was evaluated for the first time. Furthermore in vitro simulation of gastrointestinal digestion method with a dialysis step was used to take the bioavailability factor into consideration in assessing the antioxidant activity. Our results revealed the higher antioxidant capacity of brewed coffee than soluble coffee. It has been demonstrated that the honey addition to coffee as sweetener increased the total phenolic and flavonoid contents leading to a significant rise in free radical scavenging and metal reducing activities of coffee beverages, which are major parameters in assessing antioxidant capacity. Despite the fact that honey is a high 
calorie nutrient, it should be taken into account that the glycemic index of honey is much lower than sucrose [38].

\section{Materials and Methods}

\subsection{Chemicals}

All chemicals, enzymes and standards used in the experiments were purchased from Sigma Chemical Co. (St. Louis, MO, USA). All chemicals were of analytical grade.

\subsection{Coffee and honey samples}

Soluble (ready-to-use) and brewed coffee samples were purchased from stores in Istanbul. Floral and pine honey samples were provided by Altıparmak Co., Istanbul. Soluble and brewed coffee samples were prepared in a volume as suggested in their package $(13 \mathrm{~g} / 200 \mathrm{~mL})$. After the addition of pine honey or floral honey ( $7 \mathrm{~g}$; Katlaballa) into the coffee samples, they were lyophilized. The lyophilized samples were dissolved in water at proper concentrations (ND: nondigested samples) prior to analysis.

\subsection{In vitro simulation of gastrointestinal digestion}

The gastrointestinal digestion was simulated with a twostep method described by McDougall et al. [34] with slight modifications [35]. The simulated stomach solution was prepared as follows: $1.6 \mathrm{~g}$ of pepsin and $1 \mathrm{~g}$ of $\mathrm{NaCl}$ was dissolved in distilled water $(500 \mathrm{~mL})$, and the $\mathrm{pH}$ of the solution was adjusted to 2 with $5 \mathrm{M} \mathrm{HCl} .17 .5 \mathrm{~mL}$ of this solution was mixed with $2.5 \mathrm{~mL}$ of sample solution. The incubation process took place at $37^{\circ} \mathrm{C}$ in a shaking water bath for $2 \mathrm{~h}$ at $100 \mathrm{rpm}$ in order to imitate the peristaltic movement. At the end of this step, the mixture was immediately placed in an ice bath and then an aliquot of 2 $\mathrm{mL}$ was taken as "post-gastric" sample (PG) and stored at $-20{ }^{\circ} \mathrm{C}$. The remaining mixture was placed in glass beaker and a segment of cellulose dialysis tubing (molecular weight cut off $12 \mathrm{kDa}$ ) containing sufficient $\mathrm{NaHCO}_{3}$ to neutralize the titratable acidity was placed inside the beaker. Next, $4.5 \mathrm{~mL}$ of a mixture of $4 \mathrm{mg} / \mathrm{mL}$ pancreatin and $25 \mathrm{mg} /$ $\mathrm{mL}$ bile salts were added to the medium and the solution was incubated under the same conditions for additional $2 \mathrm{~h}$. Following the incubation process, the solution left outside the dialysis tubing was taken as the OUT sample representing material that remained in the gastrointestinal tract (colon available) and the solution that managed to diffuse into the dialysis tubing was taken as the IN sample (serum-available). After being centrifuged at 16,000 rpm, all of the samples were filtered through a nylon syringe filter with a pore size of $0.45 \mu \mathrm{m}$. They were stored at -20 ${ }^{\circ} \mathrm{C}$ for further analysis without exceeding the storage time not longer than one week. The amount of $1 \mathrm{M} \mathrm{NaHCO}_{3}$ required to neutralize an $18 \mathrm{~mL}$ aliquot of the post gastric digest plus $4.5 \mathrm{~mL}$ pancreatin-bile salts mixture was defined as the titratable acidity. Diffusion of $\mathrm{NaHCO}_{3}$ out of the dialysis tubing represents the simplest and most convenient method to imitate the gradual rise in $\mathrm{pH}$ that takes place as the gastric content enters the small intestine. The $\mathrm{pH}$ of OUT become neutral within $20 \mathrm{~min}$.

\subsection{Quantitative analysis of bioactive metabolites}

The total phenolic contents were measured with FolinCiocalteu method along with minor modifications spectrophotometrically [39]. The results were expressed as mg equivalents of gallic acid (GAE/g dry extract). The total flavonoid content was determined according to a previously published method [40], and the results were given as mg quercetin equivalents per $g$ sample.

\subsection{Total antioxidant capacity}

Total antioxidant capacity of every sample was calculated using phosphomolybdenum method with minor modifications [41]. The reagent solution consisted of 28 $\mathrm{mM}$ sodium phosphate monobasic, $4 \mathrm{mM}$ ammonium molybdate and $600 \mathrm{mM} \mathrm{H}_{2} \mathrm{SO}_{4}$. There hundred microliters of sample solutions were added to this reagent, and incubated at $95^{\circ} \mathrm{C}$ for $90 \mathrm{~min}$. Subsequently, the absorbance of the samples was measured at $695 \mathrm{~nm}$. The results were expressed as $\mathrm{mg}$ ascorbic acid equivalents (AAE) in $1 \mathrm{~g}$ sample.

\subsection{Free radical scavenging activity}

Free radical scavenging activity was determined by a previously published method using 1,1-diphenyl-2picrylhydrazyl (DPPH) [35]. The results were expressed as mg AAE in $1 \mathrm{~g}$ sample.

\subsection{Metal reducing capacity}

The cupric ion reducing capacity of samples were calculated according the method of Apak et al. [42]. The results were expressed as mg AAE in $1 \mathrm{~g}$ sample. 


\subsection{Statistical analysis}

All experiments were performed in triplicate. The results in each test were expressed as the mean \pm standard deviation. Statistical comparisons were made using ANOVA followed by Tukey-Kramer post hoc test for multiple comparisons. Statistically significant difference was defined as $\mathrm{p}<0.05$.

\section{Conflict of interest statement}

The authors declared no conflict of interest.

\section{References}

1. Gómez-Ruiz JÁ, Leake DS, Ames JM. In vitro antioxidant activity of coffee compounds and their metabolites. J Agric Food Chem 2007; 55: 6962-9.

2. Podio NS, Lopez-Froilan R, Ramirez-Moreno E, Bertrand L, Baroni M V, Perez-Rodriguez ML, Sánchez-Mata MC, Wunderlin DA. Matching in vitro bioaccessibility of polyphenols and antioxidant capacity of soluble coffee by boosted regression trees. J Agric Food Chem 2015; 63: 957282 .

3. Higdon JV, Frei B. Coffee and health: A review of recent human research. Crit Rev Food Sci Nutr 2006; 46: 101-23.

4. Guo X, Park Y, Freedman ND, Sinha R, Hollenbeck AR, Blair A, Chen H. Sweetened beverages, coffee, and tea and depression risk among older US adults. PLoS One 2014; 9: e94715.

5. Bonita JS, Mandrano M, Shuta D, Vinson J. Coffee and cardiovascular disease: in vitro, cellular, animal and human studies. Pharm Res 2007; 55: 187-98.

6. Willcox JK, Ash SL, Catignani GL. Antioxidants and prevention of chronic disease. Crit Rev Food Sci Nutr 2004; 44: 275-95.

7. Esquivel P, Jimenez VM. Functional properties of coffee and coffee by-products. Food Res Int 2012; 46: 488-95.

8. Tagliazucchi D, Helal A, Verzelloni E, Conte A. The type and concentration of milk increase the in vitro bioaccessibility of coffee chlorogenic acids. J Agric Food Chem 2012; 60: 1105664.

9. Anese M, Nicoli MC. Antioxidant properties of ready-todrink coffee brews. J Agric Food Chem 2003; 51: 942-6.

10. Kucukkomurler S, Özgen L. Coffee and Turkish coffee culture. Pakistan J Nutr 2009; 8: 1693-1700.

11. Jull AB, Cullum N, Dumville JC, Westby MJ, Deshpande S, Walker N. Honey as a topical treatment for wounds (Review) Cochrane Database Syst Rev 2015; 3: CD005083.

12. Gunther RT. The Greek Herbal of Dioscorides. Oxford: Oxford University Press Inc.; 1934.

13. Paul IM, Beiler J, McMonagle A, Shaffer ML, Duda L, Jr CMB. Effect of honey, dextromethorphan, and no treatment on nocturnal cough and sleep quality for coughing children and their parents. Arch Pediatr Adolesc Med 2007; 161: 1140-6.
14. Çınar SB, Ekși A, Coșkun I. Carbon isotope ratio (13C/12C) of pine honey and detection of HFCS adulteration. Food Chem 2014; 157: 10-3.

15. Raeessi MA, Raeessi N, Panahi Y, Gharaie H, Davoudi SM, Saadat A, Karimi Zarchi AA, Raeessi F, Ahmadi SM, Jalalian H. "Coffee plus honey" versus "topical steroid" in the treatment of chemotherapy-induced oral mucositis: A randomised controlled trial. BMC Complement Altern Med 2014; 14: 293.

16. Da Silva PM, Gauche C, Gonzaga LV, Costa ACO, Fett R. Honey: Chemical composition, stability and authenticity. Food Chem 2016; 196: 309-23.

17. Ekici L, Sagdic O, Silici S, Öztürk I. Determination of phenolic content, antiradical, antioxidant and antimicrobial activities of Turkish pine honey. Qual Assur Saf Crop Foods 2014; 6: 439.

18. Petretto GL, Cossu M, Alamanni MC. Phenolic content, antioxidant and physico-chemical properties of Sardinian monofloral honeys. Int J Food Sci Technol 2015; 50: 482-91.

19. Can Z, Yildiz O, Sahin H, Akyuz Turumtay E, Silici S, Kolayli S. An investigation of Turkish honeys: Their physico-chemical properties, antioxidant capacities and phenolic profiles. Food Chem 2015;180:133-41.

20. Yao LK, Liana S, Razak A, Ismail N, Fai NC, Asyraf MH, Asgar M, Sharif NM, Aan GJ, Jubri Z. Malaysian gelam honey reduces oxidative damage and modulates antioxidant enzyme activities in young and middle aged rats. J Med Plant Res 2011; 5: 5618-25.

21. Gil-Izquierdo A, Gil MI, Ferreres F, Tomas-Barberan FA. In vitro availability of flavonoids and other phenolics in orange juice. J Agric Food Chem 2001; 49: 1035-41.

22. Cämmerer B, Kroh LW. Antioxidant activity of coffee brews. Eur Food Res Technol 2006; 223: 469-74.

23. Chu YF, Chen Y, Brown PH, Lyle BJ, Black RM, Cheng IH, Ou B, Prior RL. Bioactivities of crude caffeine: Antioxidant activity, cyclooxygenase-2 inhibition, and enhanced glucose uptake. Food Chem 2012; 131: 564-8.

24. Vignoli JA, Bassoli DG, Benassi MT. Antioxidant activity, polyphenols, caffeine and melanoidins in soluble coffee: The influence of processing conditions and raw material. Food Chem 2011; 124: 863-8.

25. Chen J-T, Kotani K. Association between coffee consumption and an oxidative stress marker in women. Wien Klin Wochenschr 2015; 127: 567-9.

26. Bandera EV, Williams MG, Sima C, Bayuga S, Pulick K, Wilcox H, Zauber AG, Olson SH. Coffee and tea consumption and endometrial cancer risk: A population-based case-control study in New Jersey. Cancer Causes Control 2010; 21: 146773.

27. Malik VS, Popkin BM, Bray GA, Despres JP, Willett WC, $\mathrm{Hu}$ FB. Sugar-sweetened beverages and risk of metabolic syndrome and type 2 diabetes: A meta-analysis. Diabetes Care 2010; 33: 2477-81.

28. Whitehouse C, Boulatta J, McCauley L. The potential toxicity of artificial sweeteners. AAOHN J 2008; 56: 251-9.

29. Lien L, Lien N, Heyerdahl S, Thoresen M, Bjertness E. Consumption of soft drinks and hyperactivity, mental distress and conduct problems among adolescents in Oslo, Norway. Am J Public Health 2006; 96: 1815-20. 
30. Bouchard D, Ross R, Janssen I. Coffee, tea and their additives: Association with BMI and waist circumference. Obes Facts 2010; 3: 345-52.

31. Ozdatlı S, Sipahi H, Charehsaz M, Yesilada E, Aydın A. Effect of honey supplementation on total antioxidant capacity of herbal teas. Marmara Pharm J 2014; 18: 147-52.

32. Frankel S, Robinson G, Berenbaum M. Antioxidant capacity and correlated characteristics of 14 unifloral honeys. J Apic Res 1998; 37: 27-31.

33. Raeessi MA, Aslani J, Gharaie H, Zarchi AAK, Raeessi N, Assari S. Honey with coffee: A new finding in the treatment of persistent postinfectious cough. Iran J Otorhinolaryngol 2011; 23: $1-8$.

34. McDougall GJ, Fyffe S, Dobson P, Stewart D. Anthocyanins from red wine - Their stability under simulated gastrointestinal digestion. Phytochemistry 2005; 66: 2540-8.

35. Celep E, Charehsaz M, Akyüz S, Acar ET, Yesilada E. Effect of in vitro gastrointestinal digestion on the bioavailability of phenolic components and the antioxidant potentials of some Turkish fruit wines. Food Res Int 2015; 78: 209-15.

36. Bouayed J, Hoffmann L, Bohn T. Total phenolics, flavonoids, anthocyanins and antioxidant activity following simulated gastro-intestinal digestion and dialysis of apple varieties:
Bioaccessibility and potential uptake. Food Chem 2011; 128 : $14-21$.

37. Wong Y, Tan C, Long K, Nyam K. In vitro simulated digestion on the biostability of Hibiscus cannabinus L . seed extract. Czech J Food Sci 2014; 32: 177-81.

38. Bogdanov S, Tomislav J, Sieber R, Gallmann P. Honey for nutrition and health: A Review. Am J Coll Nutr 2008; 27: 67789.

39. Singleton VL, Rossi JA. Colorimetry of total phenolics with phosphomolybdic-phosphotungstic acid reagents. Am J Enol Vitic 1965; 16: 144-58.

40. Celep E, Aydın A, Kırmızıbekmez H, Yesilada E. Appraisal of in vitro and in vivo antioxidant activity potential of cornelian cherry leaves. Food Chem Toxicol 2013; 62: 448-55.

41. Prieto P, Pineda M, Aguilar M. Spectrophotometric quantitation of antioxidant capacity through the formation of a phosphomolybdenum complex: Specific application to the determination of vitamin E. Anal Biochem 1999; 269: 337-41.

42. Apak R, Güçlü K, Özyürek M, Karademir SE. Novel total antioxidant capacity index for dietary polyphenols and vitamins $\mathrm{C}$ and $\mathrm{E}$, using their cupric ion reducing capability in the presence of neocuproine: CUPRAC method. J Agric Food Chem 2004; 52: 7970-81. 